\title{
STUDI PEMIKIRAN PENDIDIKAN KH. AHMAD DAHLAN
}

\author{
Amirah Mawardi ${ }^{1}$ \\ Pendidikan Agama Islam Fakultas Agama Islam| Unismuh Makassar
}

\begin{abstract}
ABSTRAK
Jenis Penelitian yaitu penelitian kualitatif menggunakan pendekatan sosiologis dan historis. Selain itu juga pendekatan fenomenologis, karena itu data yang dikumpulkan lebih banyak merupakan data-data kualitatif, yaitu penelitian yang bermaksud untuk memahami fenomena tentang apa yang dialami subyek penelitian, misalnya perilaku persepsi, motivasi dan lain-lain. Berdasarkan sasaran penelitian untuk mendapatkan data kualitatif,maka digunakan beberapa metode pengumpulan data kualitatif antara lain: Observasi, wawancara dan dokumentasi. Dalam penelitian ini penulis mengumpulkan data dengan menggunakan instrumen/alat penelitian berupa pedoman obsevasi,pedoman wawancara dan catatan dokumentasi. Muhammadiyah telah berkiprah khususnya dibidang pendidikan sejak lahirnya tahun 1912 untuk kemajuan bangsa indonesia antara lain: membangun sistem pendidikan islam moderen, memperbarui paham islam, memperbarui alam pikiran ke arah kemajuan atau kemoderenan, gerakan al-maa'un (penyantu-nan) dan penolong kesengsaraan umum, membentengi umat islam dalam berbagai ancaman luar, memodernisasi kehidupan masyarakat dan mempelopori kemajuan perempuan islam ke ruang public.
\end{abstract}

\section{Kata Kunci: Studi Pemikiran, Pendidikan}

\begin{abstract}
Type of study is a qualitative study using sociological and historical approach. In addition, the phenomenological approach, because the more data collected is qualitative data, the research aims to understand the phenomenon of what is experienced research subjects, such as the behavior of perception, motivation and others. Based on the research objectives to obtain qualitative data, then used some qualitative data collection methods include: observation, interviews and documentation. In this study the authors collected data using an instrument / tool of research in the form of guidelines for observation, interview and record documentation. Muhammadiyah has been acting especially in the field of education since its inception in 1912 to the nation's progress Indonesia, among others: building a modern Islamic education system, update the understanding of Islam, renew the mind in the direction of progress or modernity, the movement of al-maa'un (penyantunan) and helper woes Generally, fortify Muslims in various external threats, modernize public life and pioneered the advancement of women Islam into public space.
\end{abstract}

Keywords: Thinking Studies, Education 


\section{PENDAHULUAN}

Pernyataan pemikiran KH. Ahmad Dahlan tersebut, merupakan spirit agar generasi muda Islam tetap yakin dengan gerakannya untuk mempertahankan Islam di bumi Indonesia. Al-hasil, dalam rentang sejarah memasuki abad ke dua Muhammadiyah (1912-2014) telah banyak melakukan usaha-usaha pencerahan dalam rangka mewujudkan tujuan Muhammadiyah, yakni menegakkan dan menjunjung tinggi agama Islam berdasarkan Al-Qur'an dan sunnah, sehingga terwujudnya masyarakat Islam yang sebenarbenarnya.(AD. Muhammadiyah Bab.I Psl. 2)

"Tidak mungkin Islam lenyap dari seluruh dunia, tetapi tidak mustahil Islam hapus dari bumi indonesia, siapakah yang bertanggung jawab?"(KH. Ahmad Dahlan dalam Yunus Salam, 1968:51)

Pernyataan pemikiran $\mathrm{KH}$. Ahmad Dahlan tersebut, telah menjadi spirit dalam tonggak sejarah memasuki abad ke dua Muhammadiyah dan efektif mencerahkan, sehingga Islam di bumi Indonesia tidak terhapus sampai saat ini. Spirit pemikiran KH. Ahmad Dahlan yang sarat makna tersebut, berlatar pada renungan atas fakta sejarah umat Islm Indonesia pra Muhammadiayah, dimana kondisi umat Islam indonesia sebagaimana kutipan berikut ini: Indonesia, diakhir abad ke 19, adalah sebuah negeri yang muram. Setelah runtuhnya kekuasaankekuasaan monarkis di nusantara, negeri ini terkoyak oleh kolonialisme, sebuah pengalaman kolektif sebagai bangsa yang menimbulkan trauma dan cedera historis. Pengalaman pahit sebagai bangsa di bawah penindasan kolonialisme itu dialami sebagian rakyat yang tenggelam dalam kemiskinan (Profil Muhammadiyah, 2000:2)

Dalam struktur pemikiran $\mathrm{KH}$. Ahmad Dahlan, terdapat lima pokok pemikiran yakni:

Pertama, bidang ekonomi, disebutkan bahwa kebijakan ekonomi liberal yang diberlakukan secara formal sejak tahun 1870 telah memberi kesempatan tidak hanya kepada pemerintah koonial, melainkan juga kepada pihak asing untuk melakukan eksploitasi terhadap sumber-sumber ekonomi di seluruh Indonesia.

Kedua, bidang keagamaan, dibidang ini Muhammadiyah telah melakukan perubahan sebagi berikut: 1) penentuan arah kiblat yang tepat dalam shalat, sebagai koreksi dari kebiasaan sebelumnya yang menghadap tempat kearah barat. 2) Penggunaan perhitungan astronomi dalam menentukan permulaan dan akhir bulan puasa (hisab), sebagai kebalikan dari pengamatan perjalanan bulan oleh petugas agama. 3) Menyelenggarakan shalat bersama di lapangan terbuka pada hari raya Islam, idul fitri, dan idul adha, sebagai ganti dari shalat serupa dalam jumlah jamaah yang lebih kecil yang di selenggarakan di mesjid. 4) Pengumpulan dan pembagian zakat fitrah dan qurban pada dua hari raya (idul fitri dan idul adha) oleh panitia khusus (amil) untuk didistribusikan kepada mereka yang berhak menerimanya.

Ketiga, bidang sosial, dalam bidang sosial dan kemasyarakatan, usaha yang dirintis oleh Muhammadiyah ialah mendirikan rumah sakit, poliklinik, rumah yatim 
piatu, yang dikelola melalui lembagalembaga dan bukan secara individual sebagaimana dilakukan orang pada umumnya. Demikian pula Muhammadiyah juga telah mewujudkan bidang bimbingan dan penyuluhan agama dalam masalahmasalah yang diperlukan dan mungkin bersifat pribadi, seperti mempelopori mendirikan Badan Penyuluhan Perkawinan (BPP) di kota-kota besar. Badan atau lembaga pendidikan sosial didalam Muhammadiyah juga ikut menangani masalah-masalah keagamaan yang akan kaitannya dengan bidang sosial, seperti penerimaan dan pembagian zakat di tangani sepenuhnya oleh PKU, yang sekaligus berwewenang sebagai badan amil (Asymuni Andurrahman, 1990:120).

Keempat, bidang dakwah, caracara dakwah yang dilakukan oleh Muhammadiyah pada awal berdirinya tidak hanya memakai cara-cara konfensional. Gerakan dakwah Muhammadiyah juga menggunakan media. Muhammadiyah melakukan penyebaran agama Islam melalui tulisan sesuai dengan perkembangan dalam bidang pendidikan dan penerbitan pada waktu itu. Muhammadiyah mencetak selebaran yang berisi do'a sehari-hari, jadwal shalat, jadwal puasa ramadhan, dan masalah agama Islam lain. Selain menerbitkan buku, Muhammadiyah sejak tahun 1916 menerbitkan soewara Muhammadiyah, sebuah majalah tentang pemahaman Muhammadiyah yang menggunakan bahasa jawa.

Kelima, bidang pendidikan, dunia pendidikan juga banyak didominasi oleh kalangan eropa dan elit terakomodasi dalam sistem pendidikan moderen yang banyak dikelola oleh pemerintah kolonial indonesia kebekuan sistem pendidikan tradisional di indonesia semakin meninggalkan mayoritas pribumi dalam ketidak berdayaan ditengah sistem sosial yang semakin moderen dan rasional. Kesadaran sebagai bangsa terjajah tidak banyak muncul dikalangan masyarakat akibat pembodohan yang secara sistematis dikelolah oleh pemerintah kolonial.Elit feodal pribumi, bahkan banyak yang tidak tercerahkan.

Di tengah kemuraman mayoritas penduduk pribumi yang tidak berdaya dalam kapitalisme kolonial itu, ada juga sekelompok kecil masyarakat pribumi yang muncul sebagai penguasa industri dan pedagang yang kuat, seperti pengusaha industri batik, rokok, kerajinan, pedagang perantara, dan pedagang keliling di daerah-daerah, seperti pekalongan, Yogyakarta, Surakarta, Kudus, Pariaman, Palembang, dan Banjarmasin. Kelompok ini merupakan kelas menengah pribumi dan juga merupakan sebagian kecil dari wiraswastawan pribumi yang mampu bersaing pada tingkat lokal dengan para penguasa dan pedagang asing seperti eropa, cina, arab, dan india yang mendominasi sektor ekonomi secara umum pada waktu itu. Sebagian besar kelas menengah pribumi ( penguasa dan pedagang pribumi) ini memiliki latar belakang agama Islam dan ikatan sosial yang kuat, satu hal yang sebenarnya paradoks dengan mayoritas pribumi yang juga muslim.

Dengan demikian, interaksi mereka dengan masyarakat dan bangsa yang lebih luas berlangsung secara reguler dan berkesinambungan, tidak hanya dalam konteks ekonomi dan pendidikan, melainkan juga dalam 
aspek sosial,kultural, dan politik. Interaksi mereka dengan masyarakat muslim dunia termasuk dengan orang indonesia yang sudah lama bermukim diluar negeri, ketika menunaikan ibadah haji maupun ketika sedang belajar di timur tengah dan mesir telah membuka kesempatan masuknya unsur-unsur baru kedalam masyarakat muslim indonesia.

Tercatat dalam sejarah
indonesia bahwa Muhammadiyah lahir pada saat umat Islam indonesia sedang mengalami pembusukan secara sistematis dengan hilangnya spiritualitas Islam untuk menangani persoalan-persoalan rasional yang terjadi dalam hidup keseharian, seperti kemiskinan, ketertindasan, kebodohan, keterbelakangan, dan lain-lain. Dalam hal inilah Muhammadiyah memiliki concern yang besar untuk memberdayakan umat Islam indonesia yang selama ratusan tahun mengalami marginalisasi kolonial diberbagai bidang kehidupan dengan menggunakan spiritualisasi Islam, yaitu melalui gerakan Islam yang organis, institusional, dan sistematis.

Berdasarkan uraian pada latar belakang tersebut, maka permasalahan yang menarik untuk dikaji secara akademik adalah sebagai berikut:

1. Bagaimana sejarah pembaharuan KH. Ahmad Dahlan?

2. Bagaimana pemikiran pendidikan KH. Ahmad Dahlan?

\section{METODE PENELITIAN}

Jenis Dan Pendekatan Penelitian yaitu penelitian kualitatif menggunakan pendekatan sosiologis dan historis. Selain itu juga pendekatan fenomenologis, karena itu data yang dikumpulkan lebih banyak merupakan data-data kualitatif, yaitu penelitian yang bermaksud untuk memahami fenomena tentang apa yang dialami subyek penelitian, misalnya perilaku persepsi, motivasi dan lain-lain.

Berdasarkan sasaran penelitian untuk mendapatkan data kualitatif,maka digunakan beberapa metode pengumpulan data kualitatif antara lain: Observasi,wawancara dan dokumentasi. Dalam penelitian ini penulis mengumpulkan data dengan menggunakan instrumen/alat penelitian berupa pedoman obsevasi,pedoman wawancara dan catatan dokumentasi.

Data yang dikumpul kemudian dianalisis dengan menggunakan perbandingan satu data dengan data yang lainnya, secara tetap membandingkan kategori dan kategori lainnya. Proses analisis data dalam penelitian ini mencakup:

a. Reduksi data, yaitu mengidentifikasi adanya satuan data terkecil yang ditemukan dalam data yang memiliki makna bila dikaitkan dengan fokus dan masalah penelitian.

b. Kategorisasi data, yaitu upaya memilah-milah satuan kedalam bagian-bagian yang memiliki kesamaan kemudian diberi label.

c. Sistensisasi, yaitu mencari kaitan antara satu kategori dengan kategori lainnya kemudian diberi label lagi.

\section{HASIL DAN PEMBAHASAN}

KH.Ahmad Dahlan, melalui Muhammadiyah telah berkiprah khususnya dibidang pendidikan sejak lahirnya tahun 1912 untuk kemajuan bangsa jauh sebelum republik indonesia tercinta lahir tahun 1945. 
Kiprah Muhammadiyah antara lain sebagai berikut:

\section{Membangun Sistem Pendidikan Islam Moderen}

Muhammadiyah diakui sebagai organisasi Islam yang paling menonjol dalam amal usaha pendidikan. Pendidikan bahkan menjadi ciri penting bahkan melekat pada gerakan Muhammadiyah. Lembaga pendidikan dari tingkat dasar hingga perguruan tinggi dimiliki Muhammadiyah, termasuk taman kanak-kanak Aisyiyah Busthanul Athfal yang terbesar di seluruh tanah air. Ciri penting dan merupakan

kepeloporan Muhammadiyah dan lembaga pendidikan yang dirintis dan dikembangkannya adalah sistem pendidikan Islam moderen yang terpadu atau holistik. Artinya pendidikan Islam yang diperkenalkan oleh Muhammadiyah memadukan pendidikan agama dan pendidikan umum dalam satu kesatuan sistem, baik dalam bentuk sekolah atau perguruan umum atau madrasah dan pondok pesantren.

Lembaga pendidikan Islam moderen yang dipelopori Muhammadiyah sejak kelahirannya merupakan alternatif dari sistem pendidikan Islam tradisional yang waktu itu hanya memperkenalkan pendidikan agama secara khusus, yang tidak responsif terhadap tantangan dan perkembangan zaman. Apa yang dirintis Muhammadiyah tersebut pada awalnya ditanggapi negatif oleh kalangan Islam tradisional karena telah memakai sistem sekolah model barat, tetapi lama-kelamaan diterima secara luas bahkan dibelakang hari ditiru dan menjadi sistem pendidikan yang berlaku umum di lingkungan umat
Islam dengan sistem pendidikan Islam moderen tersebut. Muhammadiyah menghadirkan generasi muslim terpelajar yang kuat iman dan kepribadian selaku muslim sekaligus memiliki kualitas intelektual dan kemampuan menghadapi kemajuan zaman.

\section{Memperbarui Paham Islam}

Muhammadiyah dengan semangat kembali pada Al-Qur'an dan Sunnah nabi (al-ruju'ila al-qur'an wa al-sunnah) telah berhasil meluruskan pemahaman agama yang bersifat serba taklid dan perbuatan kemusyrikan, tahayul, dan bid'ah ke paham Islam yang otentik atau murni pada al-qur'an dan sunnah nabi yang sakhihah/ maqbulah. Bagi Muhammadiyah, Islam tidak ada sumber ajarannya, yang otentik kecuali pada al-qur'an dan sunnah Nabi yang sakhiha/ maqbulah. Adapun pandangan madzhab, ulama, dan sejenisnya yang bersifat faham yang dasarnya substansi kebenarannya harus diuji oleh alqur'an dan sunnah nabi bukan sebaliknya, qaul dan pendapat ulama jangan sampai mengugurkan dan mengaburkan pandangan Al-qur'an dan sunnah Nabi yang maqbulah, apalagi menetapkan sebagai kebenaran mutlak yang harus diikuti secara taqlid atau tanpa kritis. Hal demikianlah menjadi sangat penting karena warisan ulama tersebut sering disalahkan, yang hingga saat ini ada sementara kalangan mudah yang begitu kritis bahkan berani melakukan dekonstruksi terhadap pandangan dan mazhab ulama.

Dalam kaitan ini Muhammadiyah benar-benar berhasil mendobrak kebekukan dalam paham keagamaan, sehingga Islam memiliki 
ujukan yang otentik. Bahwa sumber utama rujukan ajaran Islam itu adalah Al-Qur'an dan sunnah nabi yang maqbulah, yang harus diyakini, dipahami dan diamalkan secara mendalam dan luas pandangan sebagai fundamental dan luasnya cakrawala Islam dalam memperbaharui faham Islam yang bersumber pada ajaran yang otentik itu, Muhammadiyah mengembangkan tajdid dan ijtihad, sehingga kembali pada Al-Qur'an dan sunah nabi bukan sekedar mencari kemurnian semata (purifikasi) tetapi sekaligus pembaruan yang bersifat dinamisasi (ishlah,tajdid) disertai pengayaan baik pada aspek pemurnian maupun pengembangan, untuk kemudian membumikan Islam dalam realitas jaman sehingga Islam itu melahirkan kemajuan dan menjadi agama rahmatan lilalamin.

Gerakan

purifikasi

(pemurnian) yang cenderung keras pada periode tertentu terutama dalam pemberantasan TBC (Tahayul, Bid'ah Khurafat) harus dibaca dalam konteks dinamika gerakan,yang sering mengalami diskontinuitas atau perubahan, disamping kesinambungan atau kontinuitas. Tetapi Muhammadiyah mencoba pembaharuan cara atau metodologi dengan pendekatan dakwah kultural. Pendekatan dakwah kultural tersebut bukan berarti Muhammadiyah membenarkan TBC yang bertentangan dengan prinsip aqidah yang murni, tetapi lebih pada memperkaya pendekatan sehingga tidak serba konfrontasi yang pada akhirnya menjauhkan gerakan Islam ini dari umat awam.

\section{Memperbarui Alam Pikiran Ke arah Kemajuan Atau Kemoderenan}

Ketika Muhammadiyah lahir umat Islam khususnya dan masyarakat indonesia berada dalam keadaan tradisional yakni terkungkung oleh tradisi yang menunjukkan keadaan dan sikap yang tertinggal, terbelakang, dan jauh dari kemajuan. Umat Islam saat itu identik dengan kemiskinan, kolot, dan anti kemajuan.

Ketika Muhammadiyah lahir, umat Islam khususnya dan masyarakat Indonesia pada umumnya berada dalam keadaan tradisional, yakni terkungkung oleh tradisi menunjukkan keadaan dan sikap yang tertinggal, terbelakang, dan jauh dari kemajuan. Umat Islam saat itu identik dengan kemiskinan sebagaimana sejarah menunjukkan Islam berhasil membangun kejayaan peradaban Islam sekitar enam abad lamanya. Tradisi tidak boleh menentang dan memenjara umat atau masyarakat dalam keterbelakangan. Keberhasilannya melakukan usaha menuju kemajuan hidup di segala bidang. Muhammadiyah berhasil melakukan pembaharuan pemahaman Islam dan membangun cara hidup yang moderen sepanjang kemajuan ajaran Islam kemudian dijuluki atau diberi predikat oleh banyak pihak sebagai gerakan pembaharuan Islam atau tajdid fialIslam yang dalam istilah kontemporer disebut pula sebagai gerakan reformisme Islam atau modernisme.

Muhammadiyah hingga saat ini tetap berkomitmen untuk menawarkan pikiran-pikiran yang berkemajuan. Jangan sampai roda sejarah terulang kembali ke belakang. Tradisionalitas yang membawa kemujuran, ketinggalan, dan 
keterbelakangan tidak boleh dibiarkan dengan alasan merawat khazanah lama yang baik sesungguhnya semu dan hanya mengawetkan status-kuo. Umat Islam yang mayoritas dhuafa kemudian menjadi korban sub-kordinasi para elit tradisional yang bersembunyi di atas isu kekayaan kultural tetapi menyimpan pengawetan status-kuo penghegemoni umat. Disinilah Muhammadiyah harus tetap terpanggil menawarkan Islam yang berkemajuan, sekaligus mengucapkan selamat tinggal pada tradisional yang mengawetkan ketertinggalan dan sistem yang mengekang kehidupan Islam.

\section{Gerakan Al-Maa'un (Penyantu- nan) Dan Penolong Kesengsaraan Umum}

Muhammadiyah termasuk organisasi Islam yang mengedepankan pada pelayanan sosial dan kesehatan Muhammadiyah merintis dan mengembangkan pelayanan sosial dan kesehatan secara lembaga yang kini terus berkembang. Bagi Muhammadiyah amal usaha di bidang pelayanan sosial dan kesehatan itu bukan sekedar kariatif atau kedermawaan, tetapi merupakan gerakan pemberdayaan sebagai penolong kesengsaraan omeom (PKO). Bahwa melayani kaum miskin anak yatim dan kaum duafa lainnya merupakan panggilan keagamaan sebagai wujud konsistensi ajaran agama, sebaliknya menelantarkan dan tidak peduli pada kaum lemah itu merupakan bentuk pendustaan terhadap agama Islam melalui alma'un dan PKO Muhammadiyah menghadirkan Islam sebagai gerakan pembebasan dan pemberdayaan mayarakat.
Al-ma'un (penyantunan) bagi Muhammadiyah bukan hanya gerakan, bahkan menjadi teologi amal. Artinya melalui al-ma'un Muhammadiyah membangun alam pikiran keIslaman yang bersifat membebaskan anak-anak yatim atau miskin sebagai wujud kelibatan agama dalam memperdayaan kaum lemah dan tertindas dalam kehidupan. Surat al-ma'un mengandung isi sebagai berikut (terjemahan) : 1. Tahukah kamu(orang) yang mendustakan agama. 2. Itulah orang yang menghardik anak yatim. 3 . Dan tidak menganjurkan memberi makan orang miskin. 4. Maka kecelakaanlah bagi orang-orang yang shalat. 5. (yaitu) orang-orang yang lalai dari shalatnya. 6. Orang-orang yang membuat riya. 7. Dan enggan (menolong dengan) barang berguna (Qs. Al-ma'un)(114):1-7).

\section{Membentengi Umat Islam Dalam Berbagai Ancaman Luar}

Muhammadiyah

tanpa

menggemborkan diri melalui gerakan amal usaha dan pemberdayaannya secara langsung maupun tidak langsung sebenarnya telah memagari atau membentangi umat dari segala bentuk ancaman dari luar, termasuk ancaman kemurtadan atau pemindahan agama. Namun langkah yang dilakukan Muhammadiyah bersifat elegan, yakni tidak dengan cara konfrontasi dengan pihak lain. Muhammadiyah melakukan pendekatan kulturaldan karya nyata, sehingga tampil secara kompetitif dan objektif. Kyai Dahlan bahkan mengajak pendeta untuk berdialog dan berdebat soal kebenaran agama, dengan tetap santun dan cerdas. Gerakan inilah yang oleh Alwi Syihab disebut dengan usaha membendung 
arus. Dampak positif yang dilakukan Muhammadiyah ialah menjaga keberadaan umt Islam agar disuatu pihak tetap istiqomah dengan agamanya, tetapi pada saat yang sama diperkuat dan diberdayakan kehidupannya, sehingga lama kelamaan tumbuh dan berkembang menjadi umat yang relatif kuat.

Sejarah menunjukkan bahwa sejak jaman penjajahan portugis hingga belanda sampai pada pasca kemerdekaan umat Islam indonesia harus berlomba menghadapi golongan agama lain yang demikian ekspansif, yang sampai batas tertentu masuk kewilayah komunitas muslim. Dalam konteks sosiologis hal demikian wajar adanya terjadi di seluruh belahan dunia manapun dan oleh agama manapun terutama dari tiga agama yang bercorak ekspansionistik (memiliki watak penyebar dan disebarkan) seperti yahudi, nasrani, dan Islam. Dalam lalulintas mobilitas agamaagama itu, Muhammadiyah tidak meratapi dengan menunjukkan sikap perlawanan yang konfrontatif, tetapi menghadapinya dengan sikap berani dan dewasa yakni melalui pembentengan aqidah umat Islam sekaligus memperbaharui kondisi kehidupan mereka agar tidak rentan secara ekonomis, politik, dan budaya yang berpeluang pada kerentangan aqidah.

\section{Memodernisasi Masyarakat}

Muhammadiyah

Kehidupan melalui gerakan pembaharuan pemahaman dan pengalaman Islam yang beroreontasi pada kemajuan, amal usaha yang membawa kemaslahatan secara nyata, dan berbagai langkah dakwah masyarakat lainnya secara lansung maupun tidak langsung telah melakukan proses modernisasi sosial dalam kehidupan masyarakat indonesia. Muhammadiyah telah mempelopori perubahan sosial dari masyarakt yang berkemajuan, dan dari orientasi kehidupan yang statis kepada kehidupan yang dinamis. Karena itu, Dr. Alfian menyebut Muhammadiyah sebagai agen of social change, yakni kekuatan yang menjadi perantara sekaligus pelaku perubahan sosial.

Proses modernisasi sosial yang demikian merupakan tonggak penting dalam sejarah perkembangan masyarakat indonesia pada awal abad ke-20, ketika bangsa indonesia kala itu oleh Sutan Takdir Ali Syahbana disebut masih berada dalam kebudayaan,"praindonesia" aliran tradisional yang jauh dari nilai-nilai kemajuan. Mulai gerakan sosial kemasyarakatan dan kegemaran dalam bekerja, Muhammadiyah menurut Soekarno telah melakukan modernisasi sosial dalam kehidupan masyarakat indonesia.

\section{Mempelopori Kemajuan Perempuan Islam $\mathrm{Ke}$ ruang Publik}

Muhammadiyah melalui gerakan Aisyiyah yang dilahirkan pada tahun 1917 merupakan satu-satunya gerakan pembaharuan Islam diindonesia muslim yang berani melakukan terbosan dengan menghadirkan gerakan perempuan Islam ke ruang publik. Terobosan tersebut dikatakan berani karena seakan melawan dua arus, yaitu paham keagamaan yang masih bias gender terhadap perempuan dan budaya masyarakat yang menganut sistem patriarki, yang melahirkan diskriminasi yang sekuler-liberal, telah 
menghadirkan pembaharuan tatanan yang berkeadilan antara laki-laki dan perempuan sistem sosial muslim yang demoktratis yang berakhlak utama.

\section{KESIMPULAN}

Pemikiran KH. Ahmad Dahlan tersebut, merupakan spirit agar generasi muda Islam tetap yakin dengan gerakannya untuk mempertahankan Islam di bumi Indonesia dalam rentang sejarah memasuki abad ke dua Muhammadiyah telah banyak melakukan usaha-usaha pencerahan dalam rangka mewujudkan tujuan Muhammadiyah, yakni menegakkan dan menjunjung tinggi agama Islam berdasarkan Al-Qur'an dan sunnah, sehingga terwujudnya masyarakat Islam yang sebenar-benarnya.

Muhammadiyah telah berkiprah khususnya dibidang pendidikan sejak lahirnya tahun 1912 untuk kemajuan bangsa indonesia antara lain: membangun sistem pendidikan islam moderen, memperbarui paham islam, memperbarui alam pikiran ke arah kemajuan atau kemoderenan, gerakan al-maa'un (penyantu-nan) dan penolong kesengsaraan umum, membentengi umat islam dalam berbagai ancaman luar, memodernisasi kehidupan masyarakat dan mempelopori kemajuan perempuan islam ke ruang public.

\section{DAFTAR PUSTAKA}

Djarnawi Hadikusuma, "MatahariMatahari Muhammadiyah", (Suara Muhammadiyah: Yogyakarta, 2010)
Haedar Nashir, "Muhammadiyah Abad Kedua", (Suara Muhammadiyah: Yogyakart, 2011)

Haedar Nashir, "Muhammadiyah Gerakan Pembaharuan", (Suara Muhammadiyah:

Yogyakarta, 2010)

Haedar Nashir, "Manhaj Gerakan Muhammadiyah", (Suara Muhammadiyah: Yogyakarta, Cet. Ii, 2010)

Hujair, Ah. Sanaky, "Paradigma Pendidikan Islam", Safinia Insania Press: Yogyakarta,2003

L.Exy J Moloeng, "Metodologi Penelitian Kualitatif', (Bamdunag: PT Remaja Rosydakarya,2008)

Munir Mulkha, "Pesan Dan Kesan KH. Ahmad Dahlan", Bandung: Suara Muhammadiyah, 2010)

Mukhlas Abrar, "Muhammadiyah Persamaan Dan Kesamaan", (Gama Media Yogyakarta, 2010)

M. Amien Rais, "1 Abad Muhammadiyah; Istiqomah Membendung Kristenisasi Dan Liberalisasi" (MTDKPPM,2010)

Sigit Daryanto, "Kamus Lengkap Bahasa Indonesia", (Apollo: Surabaya, 1998)

Yusran Asrofi, “ KH. Ahmad Dahlan; Pemikiran Dan Kepemimpinannya", (MPKSDI PP. Muhammadiyah: Yogyakarta, 2005 